\section{A microcomputer program package for metaanalysis}

BERNARD S. GORMAN

Creedmoor Psychiatric Center, Queens Village, New York

LOUIS H. PRIMAVERA

St. John's University, Jamaica, New York and Creedmoor Psychiatric Center, Queen's Village, New York

and

\section{ATHAN KARRAS \\ Creedmoor Psychiatric Center, Queens Village, New York}

The term "metaanalysis" describes a group of techniques for comparing and/or combining the statistical results of several independently conducted research studies on the same topic. Within the past decade, several major advances in statistics for metaanalysis have been formulated and have been applied to areas as diverse as psychotherapy-outcome research, educational testing, and organizational psychology (Wortman, 1983). The present program consists of four BASIC computer programs designed to implement a variety of metaanalysis techniques.

EFFECT SIZE is a program based on Friedman's (1982) formulas for indexes of magnitudes of statistical effects. Program users can enter product-moment rs, $\mathrm{t}$ tests, $\mathrm{Z}$ tests, $\mathrm{F}$ ratios, or chi-square tests with associated sample sizes or degrees of freedom. Output consists of values for $r_{m}$, Friedman's magnitude-of-effect index.

The second program, ROSENTHAL, implements all of the procedures in Rosenthal's (1983) article on metaanalysis. The user can enter effect-magnitude indexes $\left(r_{m}\right.$, as obtained from EFFECT SIZE) or significance values ( $p$ ) or $Z$ values along with sample sizes. Depending upon the options selected, the output can consist of average effect sizes, an overall chi-square test of "diffuse" differences among studies, or a chi-square test that evaluates specific "focused" contrasts among studies.

The third program, CUMULATIVE ANALYSIS, computes the formulas provided by Stoffelmayr, Dillavou, and Hunter (1983). With this program, the user enters a series of effect sizes and sample sizes. The program then produces a weighted average effect size and an analysis of variability among studies that reflects: (1) total variability in effect sizes; (2) the variance in effect sizes due to sampling error; and (3) the variance in effect sizes attributable to true variation from study to study.

The final program, REGRESSION SYNTHESIS, enables users to evaluate linear multiple regression models in which effect sizes serve as dependent variables and design

The authors' mailing address is: Creedmoor Psychiatric Center, Queens Village, New York 11427. Louis H. Primavera is also with the Department of Psychology, St. John's University, Jamaica, New York 11432. characteristics of the individual studies (e.g., subjectsample characteristics of experimental conditions) serve as predictor variables. The program is based upon the weighted least squares regression formulas developed by Hedges and Olkin (1983). The program's output provides regression weights, confidence limits for regression weights, and chi-square goodness-of-fit statistics for the chosen models.

Input. EFFECT SIZE is menu driven and completely interactive. ROSENTHAL, CUMULATIVE ANALYSIS, and REGRESSION SYNTHESIS provide the user with the option of using INPUT statements for completely interactive operation or DATA statements that have been appended to the programs.

Output. All programs are written such that output can be clearly displayed on a 40-column CRT screen. Output also may be routed to a line printer.

Limitations. EFFECT SIZE uses $2 \mathrm{~KB}$. At present, ROSENTHAL can handle 400 separate studies and requires $9 \mathrm{~KB}$ of storage. CUMULATIVE ANALYSIS also has been dimensioned for 400 studies and requires $6 \mathrm{~KB}$ of storage. REGRESSION SYNTHESIS handles 100 studies and 10 independent variables and requires $24 \mathrm{~KB}$. Users can alter storage requirements by changing a few DIM statements. Program size can be decreased by packing several statements into each program line.

Computer and Language. The programs were written in APPLESOFT ${ }^{\circledR}$ BASIC for the Apple IIt. Since special machine-dependent BASIC statements were avoided, the programs should be easy to implement on most microcomputers.

Availability. Program listings and user's instructions may be obtained without charge by writing to any of the authors, Department of Program Evaluation, Creedmoor Psychiatric Center, 80-45 Winchester Boulevard, Queens Village, New York 11427. In addition, Apple or Franklin computer users may obtain programs on diskettes by mailing a 5.25-in. floppy diskette and a selfaddressed diskette mailer or a stiff, corrugated cardboard packing.

\section{REFERENCES}

Friedman, H. (1982). Simplified determinations of statistical power, magnitude of effect and research sample sizes. Educational and Psychological Measurement, 42, 521-526.

Hedaes, L. V., \& Olkin, I. (1983). Regression models in research synthesis. The American Statistician, 37, 137-140.

Rosenthal, R. Assessing the statistical and social importance of the effects of psychotherapy. (1983). Journal of Consulting and Clinical Psychology, 51, 4-13.

Stoffelmayr, B. E., Dillavou, D., \& Hunter, J. E. (1983). Premorbid functioning and outcome in schizophrenia: $\mathbf{A}$ cumulative analysis. Journal of Consulting and Clinical Psychology, 51, 338-353.

Wortman, P. M. (1983). Evaluation research: A methodological perspective. Annual Review of Psychology, 34, 223-260.

(Manuscript accepted for publication December 2, 1983.) 